\title{
Red cell membrane sodium transport: possible genetic role and use in identifying patients at risk of essential hypertension
}

\author{
J E Deal, V Shah, G Goodenough, M J Dillon
}

\begin{abstract}
To investigate the influence of a family history of essential hypertension on abnormalities of red cell membrane sodium transport, 28 hypertensive children and their families were studied. In 15 families one or both parents had either essential hypertension or a strong family history. In 13 families neither parent had essential hypertension or a positive family history. There were significant differences between the children with a positive family history of essential hypertension compared with those without. Values are expressed as mean (SD): intracellular sodium concentration (mmol// cells) $8.19(2 \cdot 18) \mathrm{com}$ pared with 6.41 (0.98); sodium efflux rate constant $0.4873(0.1379)$ compared with 0.5831 $(0.1104)$; and numbers of sodium-potassium ATPase pump sites (BMax) (nmol/1 cells) 7.96 (1.71) compared with $9.56(1.7)$. Significant differences were also found when the index hypertensive children were excluded and the normotensive siblings with and without hypertensive family histories were compared. These data suggest that abnormal red cell membrane sodium transport has a familial component, and although it is not caused by the hypertension it may be the earliest pathophysiological step in its development, perhaps allowing the identification of children at risk of essential hypertension.
\end{abstract}

Essential (primary) hypertension is an important cause of morbidity and mortality among adults, and probably has its origins in childhood. As yet, however, we do not have a means of identifying children at risk of developing it. Despite extensive research the aetiology of essential hypertension is still unclear, although many different mechanisms have been suggested. An understanding of the pathophysiological mechanisms of the development of essential hypertension, and the detection of those children who are at risk, may give us the opportunity to alter the natural history of the disease.

During recent years it has increasingly been realised that a disturbance of the transmembrane distribution of ions is a feature of hypertension in man. In particular, abnormalities of sodium transport across cell membranes have been extensively reported. Since Losse $e t$ al in 1960 first described raised intracellular sodium concentration in the red blood cells of adults with essential hypertension, ${ }^{1}$ abnormalities in other cells not directly concerned in pressure regulation (such as polymorphonuclear leuco- cytes and lymphocytes) have been reported, ${ }^{2}$ as have abnormalities in cells that are more directly concerned such as the smooth muscle cells of resistance vessels. ${ }^{4}$ Sodium transport across red blood cell membranes occurs primarily by four mechanisms to maintain the intracellular sodium concentration: the sodium-potassium ATPase dependent pump, sodium-potassium cotransport, sodiumsodium (measured as sodium-lithium) countertransport, and passive sodium diffusion. Passive diffusion of sodium occurs across the membrane along a concentration gradient. Abnormalities of the three other pathways have all been reported in essential hypertension.

Activity of the sodium-lithium countertransport pathway is increased in essential hypertension, 5 but because in man this pathway exchanges a single external sodium ion for a single internal sodium ion-and therefore will not result in any net change in intracellular sodium concentration-it seems unlikely that the pathway is of pathophysiological importance.

Activity of the sodium-potassium cotransport pathway is decreased in patients with essential hypertension. ${ }^{6}$ The pathway normally lies dormant in the cell membrane, however, unless intracellular sodium concentration rises above a critical point at which time the sodium pump is being maximally stimulated and the sodiumpotassium cotransport system is acting as a supporting mechanism for sodium extrusion. It is therefore unlikely that this pathway has any pathophysiological importance.

The sodium-potassium ATPase pump has been widely studied in essential hypertension, and we have chosen to study this pathway by measurement of the intracellular sodium concentration, the sodium efflux rate constant, and the number of sodium-potassium ATPase dependent pump sites. We have previously described abnormalities of these three measures of sodium transport in children with essential hypertension compared with normal children, and with children with secondary forms of hypertension. ${ }^{7}$ The children with essential hypertension had raised intracellular sodium concentrations, lowered sodium efflux rate constants, and decreased numbers of sodiumpotassium ATPase dependent pump sites compared with the normal children and those with secondary hypertension. There was, however, some degree of overlap of values among these three groups. It is unclear whether these abnormalities are important in the development of essential hypertension, or whether they are genetic markers. To study these 
abnormalities further and investigate the influence of a family history of hypertension we have therefore studied families with and without a history of hypertension.

\section{Subjects and methods}

We studied 28 families consisting of the parents and siblings of 28 children who presented for the investigation of mild to moderate hypertension. Of these index 28 children, 15 were subsequently found to have secondary forms of hypertension and 13 had essential or labile hypertension.

The 28 families were divided into two groups. Families in which one or other of the parents

Table 1 Details of the index children and their siblings studied. There were no significant differences between the groups.

\begin{tabular}{|c|c|c|}
\hline & $\begin{array}{l}\text { No with } \\
\text { positive family } \\
\text { history }(n=30)\end{array}$ & $\begin{array}{l}\text { No with } \\
\text { negative family } \\
\text { history }(n=28)\end{array}$ \\
\hline \multirow{6}{*}{$\begin{array}{l}\text { Male:female ratio } \\
\text { Mean (range) age (years) } \\
\text { Mean (range) systolic } \\
\text { blood pressure (mm Hg) } \\
\text { Mean (SD) systolic blood } \\
\text { pressure SD score } \\
\text { Mean (range) diastolic } \\
\text { blood pressure (mm Hg) } \\
\text { Mean (SD) diastolic blood } \\
\text { pressure SD score } \\
\text { Mean (SD) sodium } \\
\text { excretion (mmol } / \mathrm{kg} / 24 \\
\text { hours) }\end{array}$} & $\begin{array}{l}19: 11 \\
13 \cdot 79(0 \cdot 25-22 \cdot 3)\end{array}$ & $\begin{array}{l}14: 14 \\
14 \cdot 22(5 \cdot 8-33)\end{array}$ \\
\hline & $121 \cdot 4(80-166)$ & $121 \cdot 8(84-180)$ \\
\hline & $0.92(1.38)$ & $1 \cdot 16(1 \cdot 86)$ \\
\hline & $73 \cdot 2(50-94)$ & $76 \cdot 1(32-140)$ \\
\hline & $0.80(1.09)$ & $0.99(2.07)$ \\
\hline & $1.62(0.75)$ & $1.83(1.27)$ \\
\hline
\end{tabular}

had essential hypertension, or had a strong positive hypertensive family history, were defined as our 'positive family history' group; 15 families fulfilled these criteria. In 13 families neither parent was hypertensive nor had a hypertensive family history, and these families were allocated to our 'negative family history' group. We studied 58 children including the index 28 hypertensive children, 30 in the positive family history group, and 28 in the negative family history group (table 1).

Blood pressure was measured in all subjects using a randon zero sphygmomanometer. The mean of three separate recordings for each subject was obtained and expressed as SD scores using the recommendations of the first American Task Force on blood pressure control in children. ${ }^{8}$ Blood was taken for red cell sodium transport studies, and urea, electrolytes, and creatinine estimation. A random urine specimen was obtained for analysis of sodium and creatinine concentrations and from these urine sodium excretion was estimated. ${ }^{9}$

Intracellular sodium concentration was measured on washed red blood cells using a flame photometer and expressed as $\mathrm{mmol} / \mathrm{l}$ cells. Sodium efflux rate constant was measured after the incubation of red blood cells with ${ }^{22} \mathrm{Na}$ and the number of sodium-potassium ATPase dependent pump sites was estimated by measuring the binding of labelled ouabain to the red cell membrane (BMax) by the methods descri-

Table 2 Results of red cell membrane sodium transport in parents

\begin{tabular}{llll}
\hline & $\begin{array}{l}\text { Hypertensive patients } \\
(n=18)\end{array}$ & $\begin{array}{l}\text { Normotensive parents } \\
(n=36)\end{array}$ & $\begin{array}{c}p \\
\text { Value }\end{array}$ \\
\hline Mean (SD) intracellular sodium concentration (mmol// cells) & $9 \cdot 05(3 \cdot 6)$ & $6 \cdot 29(1 \cdot 45)$ & $<0 \cdot 001$ \\
Mean (SD) sodium efflux rate constant & $0 \cdot 4470(0 \cdot 1052)$ & $0.6091(0 \cdot 1500)$ & $<0 \cdot 001$ \\
Mean (SD) Bmax (nmol/l cells) & $\mathbf{8 . 0 5}(2 \cdot 05)$ & $10.96(2 \cdot 98)$ & $<0 \cdot 001$ \\
\hline
\end{tabular}
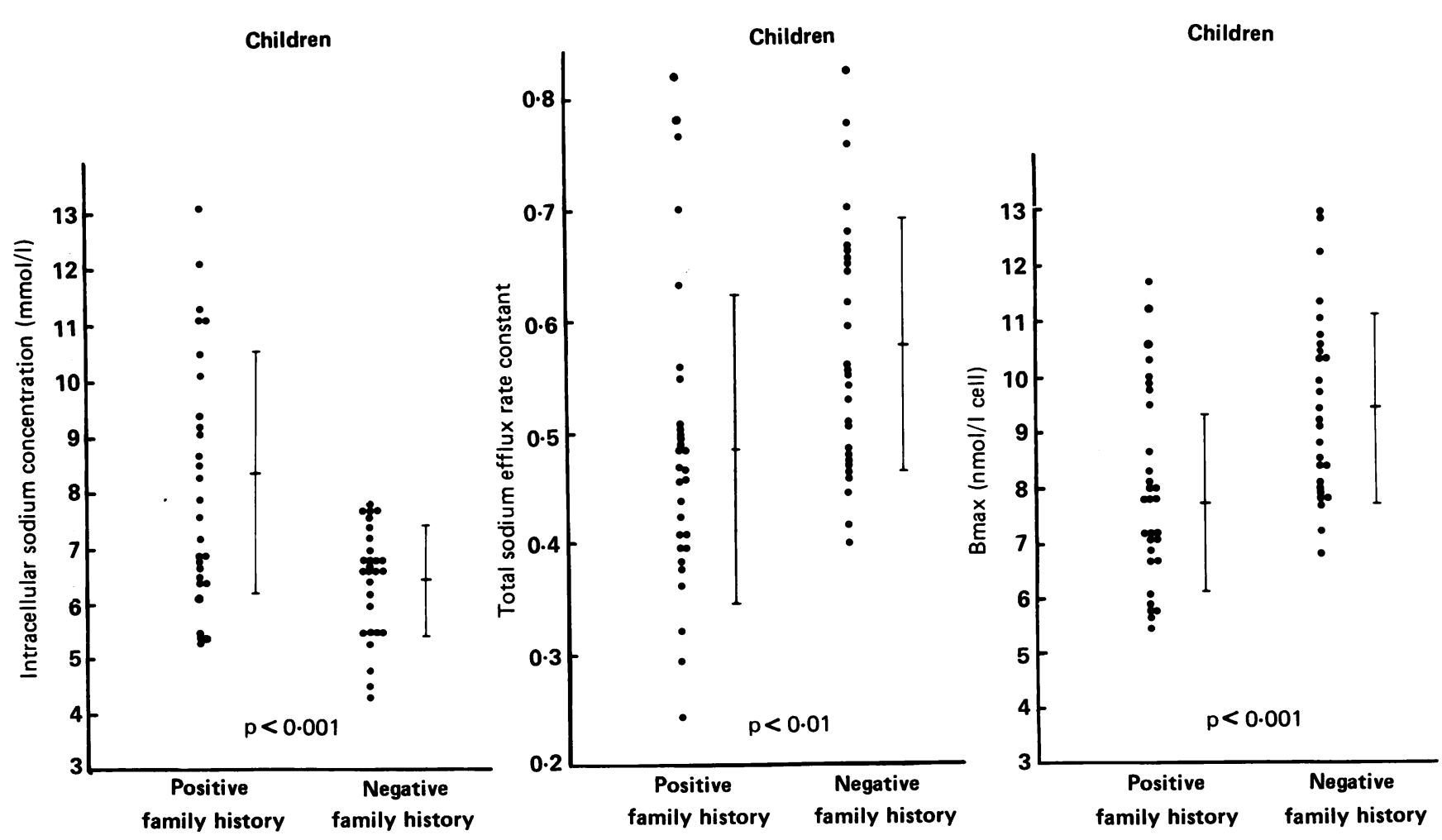

Figure 1 Results of studies of red cell membrane sodium transport in the children investigated. Those with a positive family history of hypertension $\left(n=30^{*}\right)$ are compared with those without $(n=28)$. Bars indicate mean $(S D) .{ }^{*}$ For intracellular sodium concentration, $n=28$. 

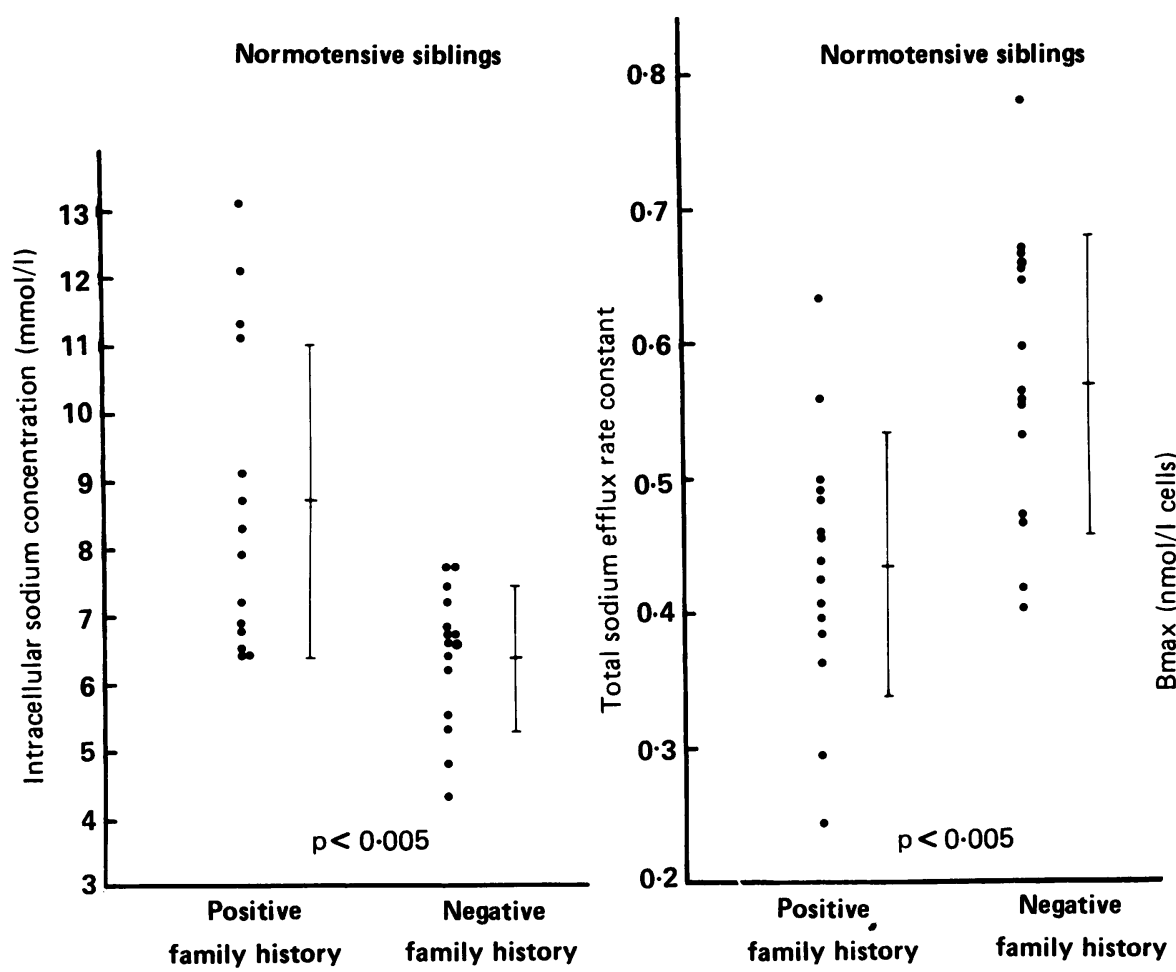

Normotensive siblings

Figure 2 Results of studies of red cell membrane sodium transport in the normotensive siblings of our index hypertensive children. Those with a positive family history of hypertension $\left(n=15^{*}\right)$ are compared with those without $(n=15)$. Bars indicate mean $(S D) .{ }^{*}$ For intracellular sodium concentration, $n=14$.

bed by Uchiyama et al. ${ }^{7}$ All red cell membrane sodium transport assays were carried out within eight hours of venesection. Results were expressed as mean (SD) and analysis was by the unpaired Student's $t$ test. A probability of $<0.05$ was accepted as significant.

\section{Results}

Parents who were hypertensive were compared with those who were normotensive (table 2 ). The hypertensive parents had significantly increased intracellular sodium concentrations, low sodium efflux rate constants, and decreased numbers of sodium/potassium ATPase dependent pump sites.

Children in the 'positive family history' group did not differ significantly from the children in the 'negative family history' group in age, blood pressure, or sodium excretion (table 1).

Children with a family history of hypertension differed significantly from those without a family history of hypertension terms of their mean (SD) intracellular sodium concentration $(\mathrm{mmol} / \mathrm{l} \mathrm{cells})$ : $8.19(2.18)$ compared with 6.41 (0.98) $(\mathrm{p}<0.001)$; sodium efflux rate constant: $0.4873(0 \cdot 1379)$ compared with $0.5831(0.1104)(\mathrm{p}<0.01)$; and numbers of sodium/potassium ATPase dependent pump sites (BMax) (nmol/l cells): 7.96 (1.71) compared with $9.56(1.7)(\mathrm{p}<0.001)$ (fig 1). These data include those of the 28 index hypertensive children. To find out if the results were being influenced by blood pressure the results were reanalysed excluding the data from the 28 index hypertensive children, and comparing the normotensive siblings with a positive family history with the normotensive siblings with a negative family history; significant differences were still found (fig 2). Siblings with a positive family history had significantly increased intracellular sodium concentrations $(\mathrm{mmol} / \mathrm{l}$ cells):8·7 $(2 \cdot 3)$ compared with $6.37(1.09)(p<0.005)$, low sodium efflux rate constants: $0.4356(0.0970)$ compared with 0.5691 $(0.1092)(p<0.005)$, and decreased numbers of sodium/potassium ATPase dependent pump sites (BMax) (nmol/l cells):7.65 (1.45) compared with $9 \cdot 79(1 \cdot 82)(\mathrm{p}<0.005)$.

\section{Discussion}

These results show that a family history of hypertension significantly influences sodium handling by red blood cells. Children-both hypertensive and normotensive - who had a positive family history of hypertension had raised intracellular sodium concentrations, low sodium efflux rate constants, and decreased numbers of sodiumpotassium ATPase pump sites as measured by Bmax when compared with children with a negative hypertensive family history.

The abnormalities of red cell membrane sodium transport were not secondary to hypertension, abnormalities being present in the normotensive siblings of our index hypertensive children, and there was no correlation between systolic or diastolic blood pressure SD scores and any of the measures of sodium transport.

Both genetic and environmental factors play a part in the pathogenesis of essential hypertension, but so far no single underlying mechanism has been identified to explain the excessive rises in blood pressure. Blaustein hypothesised that changes in cell membranes as a result of genetic or environmental factors, or both, may account for the changes in sodium fluxes seen in essential hypertension, and that the accumulation of intracellular sodium in the smooth muscle cells of resistance vessels that results from altered sodium transport interferes with sodium-calcium exchange at the cell membrane. This causes a rise in free intracellular calcium and hence an increase in smooth muscle tone and contractility, ${ }^{10}$ and could 
explain the finding of raised peripheral resistance in essential hypertension.

The familial aggregation of blood presure has been well described, and the role of heredity in its transmission has been suggested, blood pressure aggregation being the result of both a genetic component and shared environmental factors. ${ }^{11-13}$ Studies in twins have shown that a monozygotic twin of a hypertensive subject has a substantially greater risk of being hypertensive than a dizygotic twin again suggesting an important role for heredity in the aetiology of blood pressure. ${ }^{14}$ In the Montreal adoption study it was estimated that a genetic component accounted for $30 \%$ of variability in blood pressure, and that the effect of environmental factors increased with the length of cohabitation. ${ }^{16}$ Many reports have shown that essential hypertension is more common among the relatives of hypertensive than among normotensive subjects. The risk of a child becoming hypertensive increases if both parents have essential hypertension. ${ }^{17}$

Some studies of abnormalities of cellular sodium transport have shown familial aggregation, ${ }^{18-20}$ but some have shown no relationship between family history of essential hypertension and measures of sodium transport. ${ }^{21}$ These studies used different methods, and investigated other pathways of active sodium transport across the red cell membrane; they did not investigate the activity of the sodium-potassium ATPase dependent pump. The 'children' of hypertensive parents in these studies were also older than the children that we studied, and in many of the studies the children had already developed significantly higher mean blood pressures than the control groups.

Svensson and Sigstrom studied sodium pump activity in the children of hypertensive mothers. ${ }^{22}$ They compared children whose mothers had sustained hypertension after being hypertensive during pregnancy, children whose mothers were normotensive after being hypertensive during pregnancy, and a control group of children with normotensive mothers. They found no differences in intracellular sodium concentrations among their groups, but the children of hypertensive mothers had lower pump activity, although this was not significantly different from the children of normotensive mothers or the control group of children. Although they did not find a correlation between sodium pump activity and blood pressure, the children of the hypertensive mothers had higher blood pressures than their control groups.

Cooper et al investigated high school children aged 15-18 years and found significant differences in sodium pump activity between children with and without a family history of hypertension. Children with a positive family history, however, also had significantly raised diastolic blood pressures. ${ }^{23}$

Mongeau studied the cotransport and countertransport pathways in children, but did not find any association between a decrease in cotransport activity and a family history of hypertension. He did find, however, that an increased countertransport was associated with a familial tendency to hypertension. ${ }^{24}$

The abnormalities that we found are not automatically associated with increased blood pressure, and are not apparently caused by hypertension as shown by the normal results in children with secondary hypertension. They may, however, be the earliest detectable pathophysiological step in the development of raised blood pressure, and hence have some causative role. Alternatively they may just be markers, permitting the identification of children who are at risk of developing essential hypertension.

Given the large overlap in values in this study, the findings do not support the hypothesis of a monogenetic inheritance of sodium transport defects. Long term studies are required to find out if those children who have abnormal sodium transport are the hypertensive adults of the future and what environmental factors also play a part in the development of increased blood pressure.

This work was supported by the Charlotte Parkinson Research Fund, John Herring and Friends (Child Health Research Appeal Trust), and the Kidney Research Aid Fund.

1 Losse H, Wehmeyer H, Wessels F. Wasser-und Elektrolytgehalt von Erythrozyten bei arterieller Hypertonie. Klin lytgehalt von Erythrozyten
Wochenschr 1960;38:393-5.

2 Edmondson RPS, Thomas RD, Hilton PM, Patrick J, Jones NF. Abnormal leucocyte composition and sodium transport in essential hypertension. Lancet 1975;i:1003-5.

3 Ambrosioni E, Costa FV, Montebugnoli L, Tartagni F Magnani B. Increased intralymphocytic sodium content in essential hypertension: an index of impaired $\mathrm{Na}+$ cellula metabolism. Clin Sci 1981;61:181-6.

4 Aalkjaer C, Heagerty AM, Parvin SD, Bell PRF, Bing RF Swales JD. Cell membrane sodium transport: a correlation between human resistance vessels and leucocytes. Lancet 1986;i:649-51.

5 Canessa M, Adragna N, Solomon HS, Connoly TM, Tosteson DC. Increased sodium-lithium countertransport in red cells of patients with essential hypertension. $N$ Engl in red cells of patients with

6 Garay RP, Elghozi JL, Dagher G, Meyer P. Laboratory distinction between essential and secondary hypertension by measurement of erythrocyte cation fluxes. $N$ Engl $\mathcal{F} \mathrm{Med}$ measurement of er

7 Uchiyama M, Shah V, Daman Willems CE, Dillon MJ. Sodium transport in erythrocytes: differences between normal children and children with primary and secondary hypertension. Arch Dis Child 1989;64:224-8.

8 Recommendations of the task force on blood pressure contro in children. Pediatrics 1977;59:797-820.

9 Dillon MJ, Ryness JM. Plasma renin activity and aldosterone concentration in children. $\mathrm{Br}$ Med $\mathcal{F}$ 1975; iv:316-9.

10 Blaustein MP. Sodium ions, calcium ions, blood pressure regulation and hypertension: a reassessment and an hypothesis. Am f Physiol 1977;232:C165-73.

11 Miall WE, Heneage P, Khosla T. Factors influencing the degree of resemblance in arterial pressure of close relatives. degree of resemblance in art $1967 ; 33: 271-83$.

12 Zinner SH, Levy PS, Kass EH. Familial aggregation of blood pressure in childhood. $N$ Engl $\mathcal{J}$ Med 1971;284:401-4.

13 Lee YH, Rosner B, Gould JB, Lowe EW, Kass EH. Familial aggregation of blood pressure of newborn infants and their aggregation of blood pressure of new
mothers. Pediatrics 1976;58:722-9.

14 Levine RS, Hennekens CH, Perry A, Cassady J, Gelland H, Jesse MJ. Genetic variance of blood pressure levels in infan twins. Am F Epidemiol 1982;116:759-64.

15 McIllaney ML, Shaffer JW, Hines EA Jr. The heritability of blood pressure: an investigation of 200 pairs of twins using the cold pressor test. Fohns Hopkins Medical fournal 1975; 36:57-74.

16 Annest JL, Sing CF, Biron P Mongeau JG. Familial aggregation of blood pressure and weight in adoptive families. II. Estimation of the relative contributions of genetic and common environmental factors to blood pressure correlations between family members. Am $\mathcal{J}$ Epidemiol 1979;110: 492-503.

17 Miyao S, Furusho T. Genetic study of essential hypertension. $\mathcal{F p n}$ Circ $\mathcal{F}$ 1978;42:1161-86.

18 Canali M, Borghi L, Sani E, et al. Increased erythrocyte lithium-sodium countertransport in essential hypertension: its relationship to family history of hypertension. Clin Sci its relationship $1981 ; 61: 13 \mathrm{~s}-5 \mathrm{~s}$.

19 Woods JW, Falk RJ, Pittman AW, Klemmer PJ, Watson BS, Namboodiri $K$. Increased red cell sodium-lithium countertransport in normotensive sons of hypertensive parents N Engl f Med 1982;306:593-5.

20 Meyer P, Garay RP, Nazaret C, et al. Inheritance of abnormal erythrocyte cation transport in essential hypertension. $B$ Med F 1981;282:1114-7.

21 Trevisan M, Strazzullo P, Cappuccio FP, et al. Red blood cell $\mathrm{Na}$ content, $\mathrm{Na}$, Li-countertransport, family history of hypertension and blood pressure in school children. f Hypertens 1988;6:227-30.

22 Svensson A, Sigstrom L. Blood pressure, erythrocyte sodium and potassium concentrations and $\mathrm{Na}+\mathrm{K}+\mathrm{ATPase}$ activity in children with hypertensive mothers. $\mathcal{f}$ Hypertens $1986 ; 4$ : 269-72.

23 Cooper R, Miller K, Trevisan M, et al. Family history of hypertension and red cell cation transport in high school students. F Hypertens 1983;1:145-52.

24 Mongeau JG. Value of measurement of erythrocyte cation fluxes as a genetic marker in essential hypertension of adolescents and children. In: Brodehl J, Ehrich JHH, eds. Paediatric nephrology. Berlin: Springer-Verlag, 1984:382-4. 